Article

\title{
Fuzzy Multicriteria Analysis for Performance Evaluation of Internet-of-Things-Based Supply Chains
}

\author{
Santoso Wibowo $₫$ and Srimannarayana Grandhi * \\ School of Engineering \& Technology, CQUniversity, Melbourne, VIC 3000, Australia; s.wibowo1@cqu.edu.au \\ * Correspondence: s.grandhi@cqu.edu.au; Tel.: +61-3-9616-0602
}

Received: 19 October 2018; Accepted: 4 November 2018; Published: 7 November 2018

\begin{abstract}
This paper presents a fuzzy multicriteria analysis model for evaluating the performance of Internet of Things (IoT)-based supply chains. The inherent uncertainty and imprecision of the performance evaluation process was handled by using intuitionistic fuzzy numbers. A new fuzzy multicriteria group decision making algorithm based on the technique ordered preference by similarity to the ideal solution (TOPSIS) approach, and the concept of similarity measures was developed for determining the overall performance of each alternative. The advantage of the proposed fuzzy multicriteria analysis model is that it can overcome the limitations of the existing approaches in an intuitionistic fuzzy environment. The fuzzy multicriteria group decision-making model provides organizations with the ability to evaluate the performance of their IoT-based supply chains for improving their competitiveness. An example is presented to highlight the usefulness of the proposed model for tackling a real world IoT performance evaluation problem.
\end{abstract}

Keywords: group decision makers; multicriteria analysis; performance evaluation; Internet of Things; intuitionistic environment

\section{Introduction}

The Internet of Things (IoT) is a comprehensive network of electronic devices including computers and utility devices which are capable of communicating with each other [1]. It is increasingly being used in various supply chains for improving the competitiveness of individual organizations. This is because IoT can be used in supply chains to connect various devices in the network for better communication and integration of various business applications among organizations. By integrating business applications such as inventory management, customer relationship management, and business intelligence applications with suppliers, organizations can enhance communication and collaboration in the supply chain [2], leading to a reduction in cycle times and an improvement in customer services [3]. This shows that IoT-based supply chains are critical for the continuous growth of supply chains in organizations. As a result, evaluating the performance of IoT-based supply chains for development and implementation in an organization is significant.

Evaluating the performance of IoT-based supply chains is complex. This is because multiple decision makers are usually present. In addition to that, decision makers often have to deal with the conflicting nature of multiple evaluation criteria. To address this issue, it is important to have a well-defined model for systematically evaluating the overall performance of available IoT-based supply chains under uncertainty.

Earlier studies have addressed the performance evaluation of IoT-based supply chains in different contexts [4-6]. For example, Nallakaruppan and Kumaran [4] presented the technique ordered preference by similarity to the ideal solution (TOPSIS) [7] approach for evaluating the performance 
of IoT in an organization. They made use of linguistic variables to determine the weightings of each criterion and the overall performance of each alternative. A weighted normalized fuzzy decision matrix is constructed once the fuzzy ratings of the decision maker's fuzzy ratings have been obtained. The TOPSIS method is used to determine the ranking order of chosen alternatives with respect to the selected criteria. Huang et al. [5] presented the fuzzy analytical hierarchy process (AHP) [8] approach for evaluating the performance of IoT. The decision maker's judgments are represented by the triangular fuzzy numbers. Then, the concept of fuzzy synthetic extent analysis is used for determining the final result of the different criteria. Dachyar and Risky [6] presented the AHP for evaluating IoT in Indonesia's telecommunication company. This is a three-step process, which includes (a) problem breakdown, (b) judgement based on significance, and (c) priority aggregation. The initial step involves presenting the relationships between the goals of the service selection, the quality of service criteria, and the service candidates in the form of a hierarchical structure. The second step provides a comparison of selected alternatives in pairs. This helps in identifying the significance level of the criteria and the local ranking of the service candidates. The final step includes assigning ranks for the service alternatives.

These approaches, however, are incapable of dealing with the IoT-based supply chains performance evaluation in an effective manner as these methods may become cumbersome when multiple decision makers are involved in the performance evaluation process. In addition, some of these approaches require tedious mathematical computation.

This paper presents the fuzzy multicriteria group decision making model for evaluating the performance of IoT-based supply chains. The inherent uncertainty and imprecision of the performance evaluation process was handled by using intuitionistic fuzzy numbers. A new fuzzy multicriteria group decision making algorithm based on the TOPSIS approach and the concept of similarity measures was developed for determining the overall performance of each alternative. An example is presented to highlight the usefulness of the proposed model for tackling a real world IoT performance evaluation problem.

The background on the existing approaches for evaluating the performance of IoT-based supply chains and the criteria for evaluating the performance of IoT-based supply chains are presented in Section 2. We then present the fuzzy multicriteria group decision making model in Section 3. In Section 4, the fuzzy multicriteria group decision making model is tested in an illustrative example to show its usefulness for solving a real world IoT-based supply chain problem. Finally, we present the discussion and the conclusion in Section 5.

\section{Background}

The application of IoT in developing specific supply chains is critical for improving the competitiveness of organizations. This is because the adoption of IoT can improve the effectiveness and efficiency of supply chain management through obtaining precise data about vendors, stock levels, production schedules, sales, order processing, and customers and their preferences from a wide range of operating areas [9]. Such a seamless integration of information along the supply chain allows the organization to react quickly to dynamic changes in the market and to adjust stock levels, manufacturing, and transportation systems. The IoT-based supply chain allows cost reduction and better use of organizational assets without compromising the quality aspect [10].

\subsection{Existing Approaches for Evaluating the Performance of IoT-Based Supply Chains}

Several approaches have been suggested for evaluating the performance of IoT-based supply chains from different perspectives [11-16]. These approaches can be categorized into two perspectives: (a) multicriteria evaluation and (b) multiobjective optimization. Multicriteria evaluation approaches treat the multicriteria decision making problem as a discrete optimization problem. For example, Lee and Lee [12] presented the net present value method and the real option approach in justifying successful IoT system development for IoT-related organizations. Abdel-Basset et al. [13] presented 
decision making trial and evaluation laboratory model (DEMATEL) and AHP for assessing the impact of IoT on supply chains. The AHP model is used for assessing the viability of IoT applications. Wibowo [14] proposed the fuzzy approach for assessing the supply chain based on IoT capabilities in the organization. Decker et al. [15] developed the quantification cost model for evaluating IoT systems.

Multiobjective optimization approaches formulate the multicriteria decision making problem as a continuous optimization problem. These approaches mainly deal with the tangible benefits and costs in the decision process. For example, Huang et al. [16] presented the multiobjective optimization algorithm based on the chaotic ant swarm for designing IoT systems. Nunes et al. [17] proposed the vlsekriterijumska optimizacija i kompromisno resenje (VIKOR) multiobjective decision approach for evaluating the IoT capabilities in an organization. Fan et al. [18] presented the multiobjective decision making approach for evaluating the quality of service of IoT. Du et al. [19] presented the mixed-integer non-linear programming approach for the allocation of computing resources in the use of IoT. Table 1 provides the summary of the literature related to the various approaches. Meanwhile, Habib and Sarkar [20] presented an integrated approach consisting of the Analytical Network Process (ANP), the fuzzy TOPSIS, and the optimization model for dealing with temporary disaster debris management under uncertainty. In the first phase, the ANP technique is used to obtain the criteria weights. This is followed by the determination of the final ranking of the available alternatives by using TOPSIS. In the second phase, a debris allocation optimization model based on the fuzzy possibilistic programming is developed to optimize debris allocation.

Table 1. Summary of the literature related to various approaches.

\begin{tabular}{|c|c|c|c|c|}
\hline \multirow{2}{*}{ Authors } & \multicolumn{2}{|c|}{ Multicriteria Based } & \multicolumn{2}{|c|}{ Multiobjective Optimization } \\
\hline & $\begin{array}{l}\text { Multicriteria } \\
\text { Based }\end{array}$ & Cost Based & Model Objective & Model Formulation \\
\hline $\begin{array}{l}\text { Nallakaruppan and } \\
\text { Kumaran [4] }\end{array}$ & TOPSIS approach & & & \\
\hline Huang et al. [5] & $\begin{array}{l}\text { Fuzzy AHP } \\
\text { approach }\end{array}$ & & & \\
\hline Dachyar and Risky [6] & AHP approach & & & \\
\hline Lee and Lee [12] & & $\begin{array}{l}\text { Net present value } \\
\text { method and real } \\
\text { option approach }\end{array}$ & & \\
\hline Abdel-Basset et al. [13] & $\begin{array}{l}\text { DEMATEL and } \\
\text { AHP }\end{array}$ & & & \\
\hline Wibowo [14] & Fuzzy approach & & & \\
\hline Decker et al. [15] & & $\begin{array}{l}\text { Quantification cost } \\
\text { approach }\end{array}$ & & \\
\hline Huang et al. [16] & & & $\begin{array}{l}\text { Minimize design } \\
\text { problem }\end{array}$ & $\begin{array}{l}\text { Chaotic ant swarm } \\
\text { approach }\end{array}$ \\
\hline Nunes et al. [17] & & & Minimize resources & VIKOR approach \\
\hline Fan et al. [18] & & & $\begin{array}{l}\text { Minimize quality } \\
\text { of service problem }\end{array}$ & $\begin{array}{c}\text { Scale-extending, entropy } \\
\text { weight, and least squares } \\
\text { approaches }\end{array}$ \\
\hline Du et al. [19] & & & Minimize resources & $\begin{array}{l}\text { Mixed integer linear } \\
\text { programming approach }\end{array}$ \\
\hline Habib and Sarkar [20] & ANP and TOPSIS & & Debris allocation & $\begin{array}{l}\text { Fuzzy possibilistic } \\
\text { programming }\end{array}$ \\
\hline
\end{tabular}

There are several issues that are found in comparison with the TOPSIS approach presented by Habib and Sarkar [20]. Firstly, the uncertainty and imprecision of the performance evaluation process is handled by using intuitionistic fuzzy numbers instead of triangular fuzzy numbers. Secondly, multiple decision makers are involved in the decision making process which require the calculation to obtain the 
collective weighted interval-valued-based intuitionistic fuzzy performance matrix. Thirdly, the degree of indeterminacy of the relative positive and negative ideal values and the degree of similarity between the alternative and the positive and negative ideal solutions were used in this paper to determine the distance of each alternative to the positive and negative ideal solutions.

\subsection{Criteria for Evaluating the Performance of IoT-Based Supply Chains}

Much research has been performed in identifying the important criteria for determining the performance of IoT-based supply chains in different organizations [21-25]. These criteria include (a) financial cost, (b) service quality, (c) interoperability, (d) technological infrastructure, (e) reliability, and (f) security.

"Financial cost" refers to the total cost of ownership of the IoT system. This cost includes the cost of acquiring software (license fees, supporting applications, and interfaces), hardware (servers, PCs, networking equipment, and other peripherals), and maintenance of both hardware and software over the life of the IoT system [24]. On top of that, Martinho and Domingos [26] believed that the cost also covered the implementation and supporting costs of the IoT system. Meanwhile, Kouicem et al. [27] pointed out that IoT development and implementation were often associated with the high costs and high risks, and therefore it is critical for organizations to conduct a comprehensive and systematic assessment before making such a critical decision. At the same time, Brody and Pureswaran [25] identified the cost factor as the most important criteria used in the evaluation of IoT system for development and implementation.

"Quality" is the conformance to standards, and the service quality refers to the delivery of a service that conforms to or exceeds the customer's expectation. It is considered very important, as it helps to differentiate an organization's service superiority from that of the competitors'. In fact, Abdel-Basset et al. [13] highlighted the importance of service quality in service-based businesses and its support in a competitive business environment [13]. They pointed out that organizations can influence the customers' trust and commitment by improving their service quality. IoT service quality is determined by the value that the IT service brings to both the organization and its customers [22,23]. Service quality refers to the level of achievement of the IoT-based supply chain alternative to meet or exceed a customer's expectations [28]. The IoT-based supply chains are dependent on the telecommunications industry and the services offered by the telecommunications companies in that industry. Thaichon et al. [29] pointed out that the service quality in the telecommunications industry relate to providing a stable and strong network and service qualities to their customers.

In a fully integrated and well-connected network, all the IoT devices are able to communicate with the other devices or systems to exchange data instantly as needed. Each organization is equipped with different software and hardware technologies, and the interoperability between the software applications and the hardware devices is mandatory. Macaulay [30] explained that interoperability of devices in the IoT-based supply chain has significant impact on the potential economic benefits. Kryvinska and Strauss [31] believed that acquiring relevant software and interoperable devices can enhance the economic impact of IoT. Meanwhile, Dehury and Sahoo [32] stated that interoperability can promote unique solutions and offer efficiencies for IoT device manufacturers. Macaulay [30] states that interoperability is a key component in generating the potential value of IoT-based supply chains as it requires the integration of various devices across the supply chain network. While some organizations believe in achieving competitive advantage and economic incentives by building proprietary systems, this may not be feasible for IoT-based supply chains. Moreover, it can limit the overall economic opportunities and obstructs the idea of sharing data in real-time.

"Technological Infrastructure" is concerned with the integration level of an IoT system with the organization's technological infrastructure including hardware and software. If the integration is low, this may limit the communication among devices, which may lead to many malfunctions. As a result, organizations may be forced to put in additional costs to acquire additional databases and servers. Welbourne et al. [21] pointed out that the IoT would only be able to operate effectively 
through a good infrastructure. Chin et al. [33] stated that since IoT system can be used by different users from different departments in a specific organization, the integration of authorization and authentication system is a critical component. Olivier et al. [34] stated that organizations need to ensure that IoT infrastructure is selected as the infrastructure that offers reliable network for communication, security, and privacy. The IoT infrastructure consists of billions of heterogenous systems. Hence, the technological infrastructure should be capable of authenticating the devices for a reliable and secure data transmission across various administrative domains. Zanella et al. [24] believed that the challenge in the future is for an IoT application infrastructure to run quickly and consistently, especially where real-time delivery is required for determining availability and status.

Building a reliable IoT system has always been an important requirement for a business to operate successfully [35]. "Reliability" is the capability to manage a certain level of performance in the IoT-based supply chains. Although there are various sensor devices such as Global Positioning Systems (GPS) and Radio Frequency Identification Devices (RFID), it is important to maintain a certain level of performance regardless of the device type. An IoT system consists of a huge number of unique networking devices, and these are expected to connect to other devices to provide a secure and reliable communication without failure in a dynamic and unpredictable environment. To develop, implement, and manage such a secure, reliable, and error-free system, it is necessary that the IoT system is developed to be reliable. Sarkar [36] pointed out that an IoT platform must be tested for reliability under the most traffic-intensive work environments, with fault tolerance and network disaster recovery protocols mapped out.

"Security" is one of the main concerns in adopting IoT technology, and security considerations must be an integral part of the evaluation criteria before any IoT system is adopted by an organization. Additional security measures will likely be needed to ensure the integrity of both the network and the data it houses and transmits. Organizations should be capable of collecting data from various devices and protect their data from unauthorized users and hackers. In addition, a proactive approach to categorizing potential risks and developing strategies to minimize risks can increase the security of an IoT system. Hersent et al. [37] pointed out that security is critical for the secure and reliable operation of IoT-connected devices. Gubbi et al. [35] stated that security is the foundational enabler of IoT and therefore it is important that the right IoT system should be selected in order to provide an appropriate security level and ensure a reliable system performance. Farooq et al. [38] stated that organizations need to enhance privacy through a security-focused approach. This can be achieved by (a) utilizing secure devices from a reputed manufacturer, (b) collecting only required information from the IoT devices, (c) enhancing the transparency in relation to the data collected and the intended use, and (d) offering customers the choice to opt-out of data collection when they are not interested. Weber [39] believed that organizations can improve security aspect by installing appropriate security applications, developing policies, and ensuring consistent application of these policies. This will enable secure network connections among the devices and reliable data flow. Without proper security measures, it would be difficult to control unauthorized users from accessing sensitive information, attacks from hackers, and misuse of information for personal gains. Hence, a secure IoT system should be capable of restricting unauthorized users from entering its network and protect from attacks [40].

To help address this complex and challenging issue in evaluating the performance of the IoT-based supply chain alternatives, Section 3 presents the fuzzy multicriteria group decision making algorithm for evaluating the performance of IoT-based supply chains.

\section{The Fuzzy Multicriteria Group Decision Making Algorithm}

For the multicriteria group decision making problem, let $A=\left\{A_{1}, A_{2}, \ldots, A_{n}\right\}$ be the set of $n$ alternatives, and $C=\left\{C_{1}, C_{2}, \ldots, C_{m}\right\}$ be the set of $m$ criteria to be evaluated by individual decision makers $D_{k}(k=1,2, \ldots, s)$. The decision maker $D_{k}$ assessed each alternative in a form of an intuitionistic preference relation $y_{i j}^{k}=\left(\mu_{i j}^{k}, v_{i j}^{k}\right)$, and $0 \leq \mu_{i j}^{k}+v_{i j}^{k} \leq 1, \mu_{i j}^{k}=v_{i j}^{k}, v_{i j}^{k}=\mu_{i j}^{k}=0.5$ [41]. $\mu_{i j}^{k}$ indicates 
that the alternative $A_{i}$ satisfies the criterion $C_{j}$, and $v_{i j}^{k}$ indicates that the alternative $A_{i}$ does not satisfy the criterion $C_{j}$.

The procedure for the proposed algorithm included the following steps:

Step 1. Determine the performance ratings of all alternatives with respect to the criteria from each decision maker as follows:

$$
y_{i j}^{k}=\left[\begin{array}{cccc}
\mu_{11}^{k}, v_{11}^{k} & \mu_{12}^{k}, v_{12}^{k} & \ldots & \mu_{1 m}^{k}, v_{1 m}^{k} \\
\mu_{21}^{k}, v_{21}^{k} & \mu_{22}^{k}, v_{22}^{k} & \ldots & \mu_{2 m}^{k}, v_{2 m}^{k} \\
\ldots & \ldots & \ldots & \ldots \\
\mu_{n 1}^{k}, v_{n 1}^{k} & \mu_{n 2}^{k}, v_{n 2}^{k} & \ldots & \mu_{n m}^{k}, v_{n m}^{k}
\end{array}\right]
$$

Step 2. Determine the relative importance of the evaluation criteria $C_{j}$ for each decision maker as in Equation 2:

$$
w_{j}^{k}=\left(w_{1}^{k}, w_{2}^{k}, \ldots, w_{m}^{k}\right)
$$

where $w_{j}^{k}=\left(\mu_{j}^{k}, v_{j}^{k}\right)$.

Step 3. Obtain the overall intuitionistic fuzzy decision matrix of each alternative as given in Equation 3:

$$
X=\left[\begin{array}{cccc}
x_{11} & x_{12} & \cdots & x_{1 m} \\
x_{21} & x_{22} & \cdots & x_{2 m} \\
\cdots & \cdots & \cdots & \cdots \\
x_{n 1} & x_{n 2} & \cdots & x_{n m}
\end{array}\right]
$$

Step 4. Determine the overall intuitionistic fuzzy weight vector of each alternative as shown in Equation 4:

$$
W=\left(w_{1}, w_{2}, \ldots, w_{j}, \ldots, w_{m}\right)
$$

Step 5. Calculate the collective weighted interval-valued-based intuitionistic fuzzy performance matrix:

$$
R=\left[\begin{array}{cccc}
r_{11} & r_{12} & \cdots & r_{1 m} \\
r_{21} & r_{22} & \cdots & r_{2 m} \\
\cdots & \cdots & \cdots & \cdots \\
r_{n 1} & r_{n 2} & \cdots & r_{n m}
\end{array}\right]
$$

Step 6. Calculate the fuzzy positive ideal solution and the fuzzy negative ideal solution using Equations (6) and (7), respectively:

$$
\begin{aligned}
\alpha^{+}=\left(\alpha_{1}^{+}, \alpha_{2}^{+}, \ldots, \alpha_{m}^{+}\right)=\{ & \left\langle\left(\left[\left(\max _{i} \mu_{i j}\right)\left|j \in J_{1},\left(\min _{i} v_{i j}\right)\right| j \in J_{2}\right)\right],\right. \\
& {\left.\left.\left.\left[\left(\min _{i} \mu_{i j}\right)\left|j \in J_{1},\left(\max _{i} v_{i j}\right)\right| j \in J_{2}\right]\right)\right\rangle i=1,2, \ldots, n\right\} }
\end{aligned}
$$

where $\alpha_{j}^{+}=\left[\mu_{j}^{+}, v_{j}^{+}\right]$and $(j=1,2, \ldots, m)$.

$$
\begin{aligned}
\alpha^{-}=\left(\alpha_{1}^{-}, \alpha_{2}^{-}, \ldots, \alpha_{m}^{-}\right)=\{ & \left\{\left\langle\left(\left[\left(\min _{i} \mu_{i j}\right)\left|j \in J_{1},\left(\max _{i} v_{i j}\right)\right| j \in J_{2}\right)\right],\right.\right. \\
& {\left.\left.\left.\left[\left(\max _{i} \mu_{i j}\right)\left|j \in J_{1},\left(\min _{i} v_{i j}\right)\right| j \in J_{2}\right]\right)\right\rangle i=1,2, \ldots, n\right\} }
\end{aligned}
$$

where $\alpha_{j}^{-}=\left[\mu_{j}^{-}, v_{j}^{-}\right]$.

Step 7. Calculate the degree of indeterminacy of the relative positive ideal value and the relative negative ideal value using Equations (8) and (9), respectively:

$$
\begin{aligned}
& \pi_{j}^{+}=1-\mu_{j}^{+}-v_{j}^{+} \\
& \pi_{j}^{-}=1-\mu_{j}^{-}-v_{j}^{-}
\end{aligned}
$$


Step 8. Calculate the degree of similarity $[42,43]$ between the alternative $A_{i}$ and the positive ideal solution and the negative solution using Equations (10) and (11), respectively:

$$
\begin{aligned}
& G_{i}^{+}=1-\frac{\left|2\left(\mu_{j}^{+}-\mu_{i j}\right)\left(v_{j}^{+}-v_{i j}\right)\right|}{3} \times\left(1-\frac{\pi_{j}^{+}+\pi_{i j}}{2}\right)-\frac{\left|2\left(v_{j}^{+}-v_{i j}\right)\left(\mu_{j}^{+}-\mu_{i j}\right)\right|}{3} \times\left(\frac{\pi_{j}^{+}+\pi_{i j}}{2}\right) \\
& G_{i}^{-}=1-\frac{\left|2\left(\mu_{j}^{-}-\mu_{i j}\right)\left(v_{j}^{-}-v_{i j}\right)\right|}{3} \times\left(1-\frac{\pi_{j}^{-}+\pi_{i j}}{2}\right)-\frac{\left|2\left(v_{j}^{-}-v_{i j}\right)\left(\mu_{j}^{-}-\mu_{i j}\right)\right|}{3} \times\left(\frac{\pi_{j}^{-}+\pi_{i j}}{2}\right)
\end{aligned}
$$

Step 9. Calculate the overall performance index value for each alternative across all the criteria:

$$
P_{i}=\frac{G_{i}^{-}}{G_{i}^{-}+G_{i}^{+}} i=1,2, \ldots, n
$$

\section{An Illustrative Example}

This section presents the proposed fuzzy multicriteria group decision making model for evaluating the performance of an IoT-based supply chain at a high-technology manufacturing company.

A manufacturing company in Taiwan decides to develop and implement an IoT-based supply chain for meeting the challenges in the electronics manufacturing sector. This company is a top provider of innovative products in Taiwan and is ranked among top three in the global market for all its product lines. This company entered the Taiwanese light emitting diodes (LED) industry where it enjoyed the number one status for over thirty years because of its innovative products for both local and global markets. Its product line includes imaging products, enclosures, power supplies, and LEDs.

Through the adoption of the IoT-based supply chain initiative, the company believes that it will continue to be one of the leaders in the electronics manufacturing sector and, at the same time, improve its customers' overall satisfaction. Hence, the establishment of an IoT-based supply chain is essential for the success of the company.

In order to select and develop the most suitable IoT-based supply chain for the company, a committee consisting of three departmental managers was formed. Six IoT-based supply chain alternatives and six evaluation criteria were identified.

These evaluation criteria included the financial cost $\left(C_{1}\right)$, service quality $\left(C_{2}\right)$, functionality $\left(C_{3}\right)$, technological infrastructure $\left(C_{4}\right)$, reliability $\left(C_{5}\right)$ and security $\left(C_{6}\right)$. The hierarchical structure of the IoT-based supply chain performance evaluation is shown in Figure 1.

Financial cost $\left(C_{1}\right)$ is concerned with the financial ability of the organization to develop and implement the IoT-based supply chain alternative. This was determined by the costs associated with hardware (PCs, servers, networking equipment, and other peripherals), software (operating systems, application software, security and networking software, and other special software necessary for facilitating communication among various devices on the network), implementation of hardware and software, and management of the devices and software over the life of the IoT system [14,42].

Service quality $\left(C_{2}\right)$ refers to the level of achievement of the IoT-based supply chain alternative to meet or exceed a customer's expectations [28]. This is often measured by the information system quality, the process performance, the level of customer satisfaction, and the distribution network quality [28].

Interoperability $\left(C_{3}\right)$ of an IoT system is the ability to offer good services to its subscribers and receive services from others as needed. The interoperability enables communication among devices and facilitates information exchange among organizations [30]. The interoperability aspect was assessed by measuring the technical compliance of the devices, their ability to connect to the other devices, operational feasibility of these devices, and the overall interoperability of the system.

Technological infrastructure $\left(C_{4}\right)$ refers to the ability of electronic devices interconnected through the IoT to provide prompt and effective service to its end-users. This was measured by the efficiency of the system, the collaboration capabilities with other systems, and the portability of the system [44]. 
Reliability $\left(C_{5}\right)$ is a concerned with the assurance that the IoT system is free from hardware failures, software faults, and other defects that could make them break down [39]. For example, sensors such as GPS and RFID devices need to be standardized to promote reliable communication. This was measured by the fault tolerance, the connectivity of the system, the recoverability of the system, and the robustness of the system.

Security is often cited as one of the most important challenges in IoT deployment due to a huge number of networking devices with varying protocols. Hence, security at both the device and network levels is considered important for the implementation and operation of IoT. Security $\left(C_{6}\right)$ refers to the capability of safeguarding all IoT-connected devices and networks. This was measured by the level of access control, the level of device authentication, the level of encryption, and other robust security measures [36].

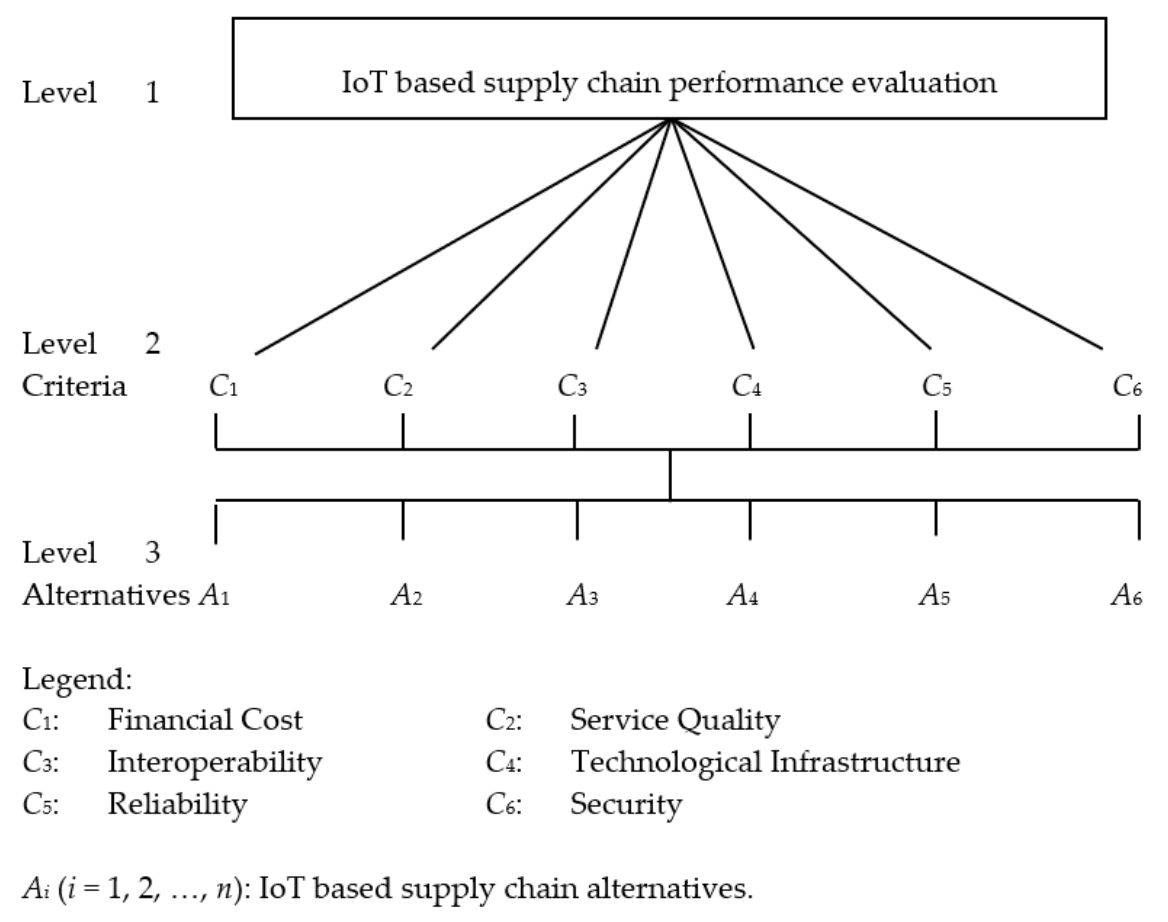

Figure 1. The hierarchical structure of the IoT-based supply chain performance evaluation.

The procedure for the performance evaluation of the IoT-based supply chains contained the following steps:

Step 1. The performance ratings of all alternatives with respect to the criteria from each decision maker were obtained as shown in Table 2.

Step 2. The criteria weights of were obtained from each decision maker as shown in Table 3.

Steps 3-5. The collective weighted interval-valued-based intuitionistic fuzzy performance matrix could be calculated as in Table 4.

Steps 6-9. The overall performance index for each alternative could be determined. Table 5 shows the results. The results showed that alternative $A_{3}$ had the highest performance index value of 0.71 as compared to other alternatives.

Figure 2 shows the performance index values of all the alternatives with respect to all the criteria. The results in Table 5 also provided the company with relevant information about the performance level of individual IoT-based supply chain. Although alternative $A_{3}$ was the most suitable alternative, it does not have competitive advantages in all performance criteria. At the same time, alternative $A_{1}$ required improvement of its performances in all criteria, especially in service quality and resource consumption. Despite being the best performer, alternative $A_{3}$ was not the best in terms of resource consumption. Meanwhile, alternative $A_{5}$ was not one of the most suitable alternatives and needed to improve its 
performance in all criteria, particularly in financial cost. The result can thus help organizations to identify the relative weaknesses of the available alternatives for improving its competitiveness.

In order to investigate the sensitivity of the output on the alternatives, we used an example in Table 6 to show the changes on the criteria weights. Figure 3 shows the changes on the performance index values and the ranking of the alternatives.

Table 2. Performance assessments of IoT-based supply chain alternatives.

\begin{tabular}{cccccccc}
\hline$A_{\mathbf{i}}$ & $D_{\mathbf{k}}$ & $C_{\mathbf{1}}$ & $C_{\mathbf{2}}$ & $C_{\mathbf{3}}$ & $C_{\mathbf{4}}$ & $C_{5}$ & $C_{\mathbf{6}}$ \\
\hline \multirow{4}{*}{$A_{1}$} & $D_{1}$ & $(0.6,0.7)$ & $(0.3,0.6)$ & $(0.4,0.6)$ & $(0.3,0.6)$ & $(0.5,0.6)$ & $(0.5,0.6)$ \\
& $D_{2}$ & $(0.5,0.8)$ & $(0.5,0.7)$ & $(0.4,0.7)$ & $(0.4,0.5)$ & $(0.5,0.7)$ & $(0.5,0.8)$ \\
& $D_{3}$ & $(0.5,0.6)$ & $(0.3,0.4)$ & $(0.7,0.8)$ & $(0.5,0.7)$ & $(0.4,0.6)$ & $(0.7,0.8)$ \\
\hline \multirow{4}{*}{$A_{2}$} & $D_{1}$ & $(0.3,0.6)$ & $(0.5,0.6)$ & $(0.3,0.5)$ & $(0.5,0.8)$ & $(0.4,0.8)$ & $(0.1,0.3)$ \\
& $D_{2}$ & $(0.5,0.7)$ & $(0.5,0.8)$ & $(0.6,0.8)$ & $(0.6,0.7)$ & $(0.3,0.7)$ & $(0.7,0.8)$ \\
& $D_{3}$ & $(0.2,0.6)$ & $(0.7,0.8)$ & $(0.5,0.9)$ & $(0.3,0.6)$ & $(0.5,0.9)$ & $(0.4,0.6)$ \\
\hline \multirow{4}{*}{$A_{3}$} & $D_{1}$ & $(0.4,0.5)$ & $(0.3,0.4)$ & $(0.3,0.6)$ & $(0.4,0.8)$ & $(0.6,0.8)$ & $(0.5,0.7)$ \\
& $D_{2}$ & $(0.3,0.7)$ & $(0.7,0.8)$ & $(0.5,0.8)$ & $(0.6,0.8)$ & $(0.3,0.6)$ & $(0.5,0.6)$ \\
& $D_{3}$ & $(0.5,0.6)$ & $(0.1,0.3)$ & $(0.7,0.8)$ & $(0.5,0.6)$ & $(0.3,0.8)$ & $(0.6,0.8)$ \\
\hline \multirow{4}{*}{$A_{4}$} & $D_{1}$ & $(0.4,0.8)$ & $(0.6,0.8)$ & $(0.4,0.7)$ & $(0.3,0.6)$ & $(0.5,0.6)$ & $(0.5,0.7)$ \\
& $D_{2}$ & $(0.3,0.4)$ & $(0.4,0.7)$ & $(0.6,0.9)$ & $(0.3,0.5)$ & $(0.3,0.6)$ & $(0.7,0.8)$ \\
& $D_{3}$ & $(0.7,0.8)$ & $(0.5,0.6)$ & $(0.5,0.8)$ & $(0.5,0.7)$ & $(0.5,0.7)$ & $(0.5,0.6)$ \\
\hline \multirow{4}{*}{$A_{5}$} & $D_{1}$ & $(0.5,0.7)$ & $(0.3,0.8)$ & $(0.6,0.8)$ & $(0.5,0.7)$ & $(0.6,0.9)$ & $(0.6,0.7)$ \\
& $D_{2}$ & $(0.5,0.6)$ & $(0.4,0.6)$ & $(0.3,0.6)$ & $(0.5,0.6)$ & $(0.5,0.8)$ & $(0.6,0.8)$ \\
& $D_{3}$ & $(0.7,0.8)$ & $(0.5,0.8)$ & $(0.5,0.8)$ & $(0.6,0.8)$ & $(0.4,0.6)$ & $(0.3,0.6)$ \\
\hline \multirow{4}{*}{$A_{6}$} & $D_{1}$ & $(0.2,0.6)$ & $(0.6,0.7)$ & $(0.4,0.6)$ & $(0.4,0.5)$ & $(0.4,0.7)$ & $(0.4,0.8)$ \\
& $D_{2}$ & $(0.7,0.8)$ & $(0.5,0.6)$ & $(0.3,0.7)$ & $(0.7,0.8)$ & $(0.6,0.8)$ & $(0.5,0.7)$ \\
& $D_{3}$ & $(0.5,0.6)$ & $(0.4,0.7)$ & $(0.5,0.6)$ & $(0.3,0.4)$ & $(0.4,0.6)$ & $(0.5,0.6)$ \\
\hline
\end{tabular}

Table 3. Criteria weights of IoT-based supply chain alternatives.

\begin{tabular}{cccc}
\hline \multirow{2}{*}{ Criteria } & \multicolumn{3}{c}{ Decision Makers } \\
\cline { 2 - 4 } & $\boldsymbol{D}_{\mathbf{1}}$ & $\boldsymbol{D}_{\mathbf{2}}$ & $\boldsymbol{D}_{\mathbf{3}}$ \\
\hline$C_{1}$ & $(0.6,0.3)$ & $(0.5,0.1)$ & $(0.7,0.3)$ \\
$C_{2}$ & $(0.5,0.4)$ & $(0.4,0.3)$ & $(0.5,0.4)$ \\
$C_{3}$ & $(0.2,0.5)$ & $(0.3,0.6)$ & $(0.6,0.4)$ \\
$C_{4}$ & $(0.6,0.8)$ & $(0.2,0.5)$ & $(0.8,0.6)$ \\
$C_{5}$ & $(0.4,0.2)$ & $(0.7,0.3)$ & $(0.4,0.3)$ \\
$C_{6}$ & $(0.7,0.3)$ & $(0.5,0.4)$ & $(0.5,0.3)$ \\
\hline
\end{tabular}

Table 4. The collective weighted intuitionistic fuzzy performance matrix.

\begin{tabular}{ccccccc}
\hline$A_{\mathbf{i}}$ & $\boldsymbol{C}_{\mathbf{1}}$ & $\boldsymbol{C}_{\mathbf{2}}$ & $\boldsymbol{C}_{\mathbf{3}}$ & $\boldsymbol{C}_{\mathbf{4}}$ & $\boldsymbol{C}_{\mathbf{5}}$ & $\boldsymbol{C}_{\mathbf{6}}$ \\
\hline$A_{1}$ & $(0.52,0.64)$ & $(0.58,0.63)$ & $(0.67,0.75)$ & $(0.51,0.62)$ & $(0.43,0.48)$ & $(0.42,0.51)$ \\
$A_{2}$ & $(0.37,0.46)$ & $(0.46,0.57)$ & $(0.41,0.49)$ & $(0.35,0.46)$ & $(0.44,0.52)$ & $(0.52,0.59)$ \\
$A_{3}$ & $(0.73,0.87)$ & $(0.56,0.71)$ & $(0.68,0.76)$ & $(0.63,0.68)$ & $(0.55,0.64)$ & $(0.37,0.64)$ \\
$A_{4}$ & $(0.68,0.73)$ & $(0.52,0.58)$ & $(0.54,0.61)$ & $(0.55,0.63)$ & $(0.35,0.46)$ & $(0.56,0.71)$ \\
$A_{5}$ & $(0.44,0.58)$ & $(0.36,0.62)$ & $(0.48,0.54)$ & $(0.52,0.59)$ & $(0.63,0.68)$ & $(0.47,0.63)$ \\
$A_{6}$ & $(0.48,0.53)$ & $(0.48,0.55)$ & $(0.54,0.62)$ & $(0.43,0.52)$ & $(0.55,0.63)$ & $(0.38,0.53)$ \\
\hline
\end{tabular}


Table 5. The performance index of IoT-based supply chains and their rankings.

\begin{tabular}{|c|c|c|c|c|c|c|c|c|c|c|c|c|c|c|}
\hline \multirow{3}{*}{ Alternatives } & \multicolumn{12}{|c|}{ Criteria } & & \\
\hline & \multicolumn{2}{|c|}{ Financial Cost $\left(C_{1}\right)$} & \multicolumn{2}{|c|}{ Service Quality $\left(C_{2}\right)$} & \multicolumn{2}{|c|}{ Functionality $\left(C_{3}\right)$} & \multicolumn{2}{|c|}{ Technological Infrastructure $\left(C_{4}\right)$} & \multicolumn{2}{|c|}{ Reliability $\left(C_{5}\right)$} & \multicolumn{2}{|c|}{ Security $\left(C_{6}\right)$} & \multicolumn{2}{|c|}{ Overall } \\
\hline & Index & Ranking & Index & Ranking & Index & Ranking & Index & Ranking & Index & Ranking & Index & Ranking & Index & Ranking \\
\hline$A_{1}$ & 0.68 & 2 & 0.58 & 5 & 0.61 & 4 & 0.64 & 3 & 0.54 & 3 & 0.66 & 4 & 0.63 & 3 \\
\hline$A_{2}$ & 0.56 & 5 & 0.51 & 6 & 0.54 & 6 & 0.51 & 6 & 0.53 & 6 & 0.53 & 6 & 0.52 & 6 \\
\hline$A_{3}$ & 0.70 & 1 & 0.73 & 1 & 0.67 & 2 & 0.71 & 1 & 0.72 & 2 & 0.74 & 1 & 0.71 & 1 \\
\hline$A_{4}$ & 0.63 & 3 & 0.70 & 2 & 0.70 & 1 & 0.67 & 2 & 0.69 & 1 & 0.71 & 2 & 0.68 & 2 \\
\hline$A_{5}$ & 0.52 & 6 & 0.62 & 4 & 0.57 & 5 & 0.55 & 5 & 0.52 & 5 & 0.56 & 5 & 0.54 & 5 \\
\hline$A_{6}$ & 0.61 & 4 & 0.65 & 3 & 0.64 & 3 & 0.59 & 4 & 0.61 & 4 & 0.58 & 3 & 0.61 & 4 \\
\hline
\end{tabular}


Table 6. Change of criteria weights for sensitivity analysis.

\begin{tabular}{cccc}
\hline \multirow{2}{*}{ Criteria } & \multicolumn{3}{c}{ Decision Makers } \\
\cline { 2 - 4 } & $\boldsymbol{D}_{\mathbf{1}}$ & $\boldsymbol{D}_{\mathbf{2}}$ & $\boldsymbol{D}_{\mathbf{3}}$ \\
\hline$C_{1}$ & $(0.8,0.2)$ & $(0.6,0.1)$ & $(0.8,0.2)$ \\
$C_{2}$ & $(0.6,0.3)$ & $(0.5,0.2)$ & $(0.6,0.5)$ \\
$C_{3}$ & $(0.2,0.5)$ & $(0.3,0.2)$ & $(0.6,0.3)$ \\
$C_{4}$ & $(0.4,0.8)$ & $(0.2,0.1)$ & $(0.4,0.2)$ \\
$C_{5}$ & $(0.3,0.1)$ & $(0.6,0.4)$ & $(0.5,0.4)$ \\
$C_{6}$ & $(0.6,0.2)$ & $(0.4,0.3)$ & $(0.3,0.2)$ \\
\hline
\end{tabular}

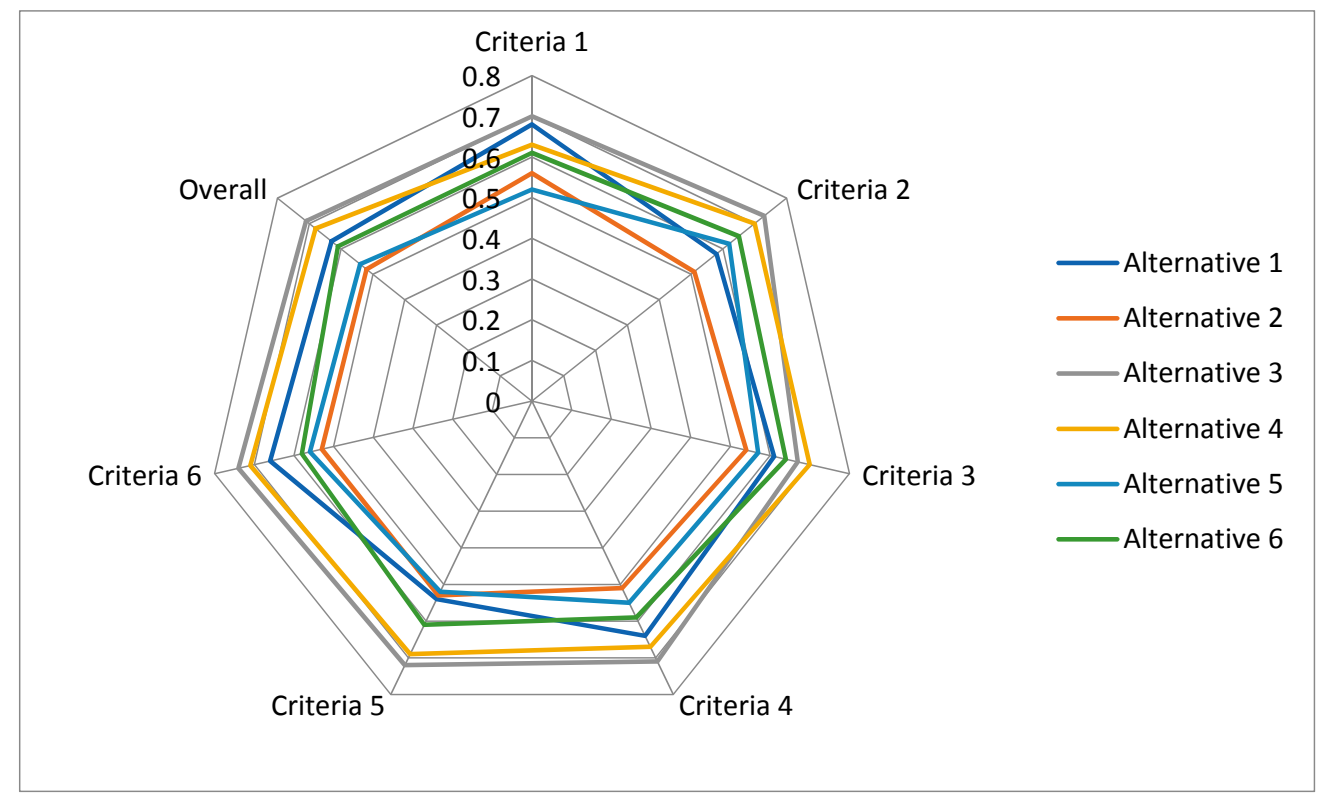

Figure 2. The performance index values of alternatives with respect to each criterion.

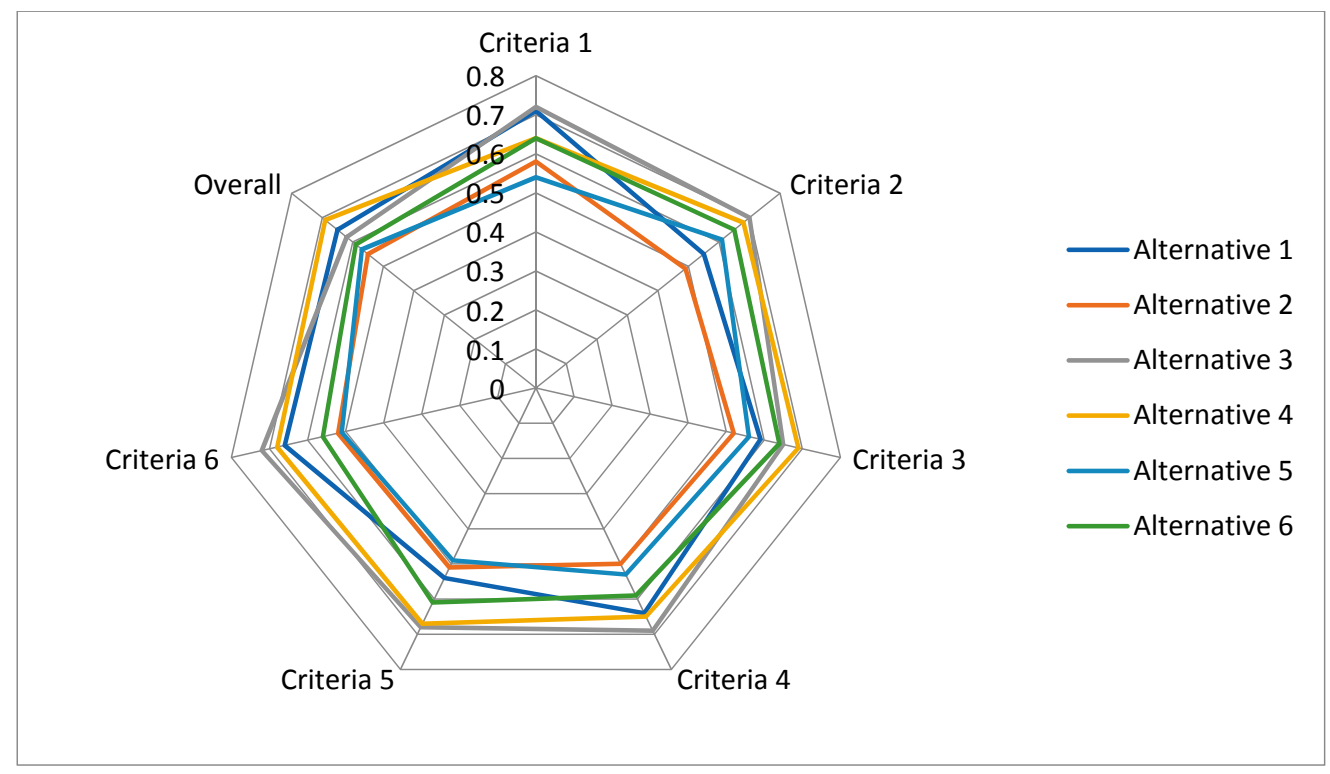

Figure 3. Sensitivity analysis on the change of the ranking of alternatives.

A comparative study of the fuzzy multicriteria group decision making algorithm was also conducted with four other approaches [42,45-47]. Table 7 shows that the fuzzy multicriteria group decision making algorithm produces consistent results as compared to other approaches. The proposed 
fuzzy multicriteria group decision making algorithm proved to be effective due to its simplicity in concept and its efficiency in computation.

Table 7. Results of the comparative study.

\begin{tabular}{cc}
\hline Approaches & Ordering \\
\hline Lin et al. [45] & $A_{3}>A_{4}>A_{1}>A_{5}>A_{2}>A_{6}$ \\
Xia and Xu [46] & $A_{3}>A_{4}>A_{1}>A_{5}>A_{6}>A_{2}$ \\
Wibowo and Deng [42] & $A_{3}>A_{4}>A_{1}>A_{6}>A_{2}>A_{5}$ \\
Hashemi et al. [47] & $A_{3}>A_{4}>A_{1}>A_{6}>A_{5}>A_{2}$ \\
The proposed algorithm & $A_{3}>A_{4}>A_{1}>A_{6}>A_{5}>A_{2}$ \\
\hline
\end{tabular}

There were several managerial insights in this study. Firstly, the potential economic impact of IoT-based supply chains is estimated to be more than $\$ 11$ trillion in the next six years [3]. On top of this, IoT-based supply chains are expected to offer significant cost savings and business agility [22]. The failure to evaluate and select the most suitable IoT-based supply chain for development and implementation can be a lost opportunity. This study provided a step-by-step approach to help managers evaluate and select the most suitable IoT-based supply chain for improving their organizations' overall performance. Secondly, the fuzzy multicriteria group decision making model was capable of handling evaluation problems associated with various alternatives and multiple criteria. Thirdly, the criteria discussed in Section 2 were specific for evaluating the performance of IoT-based supply chains. The evaluation of selection criteria showed that to succeed in adopting IoT-based supply chains, managers have to focus on critical criteria such as financial cost, service quality, functionality, technological infrastructure, reliability, and security. Finally, the proposed fuzzy multicriteria group decision making model can be used to help organizations evaluate and select their IoT-based supply chains in the most effective and efficient way.

\section{Discussion and Conclusions}

The IoT-based supply chain performance evaluation is challenging due the involvement of multiple decision makers, the multi-dimensional nature of the evaluation process, and the existence of uncertainty and imprecision in the decision making process. As a result, how the presence of multiple decision makers and the multi-dimensional nature of the evaluation process are handled and the adequate modeling of the uncertainty and imprecision have become critical issues for effectively dealing with the IoT-based supply chain performance evaluation problem in a real world setting.

This paper has presented a fuzzy multicriteria group decision making model for evaluating the performance of IoT-based supply chain alternatives. The inherent uncertainty and imprecision of the evaluation process was handled by using intuitionistic fuzzy numbers. A new fuzzy multicriteria group decision making algorithm based on the TOPSIS approach and the concept of similarity measures was developed for determining the overall performance of each alternative. The results showed that the developed fuzzy multicriteria group decision making model was capable of solving the IoT-based supply chain performance evaluation problem effectively. The advantage of the proposed fuzzy multicriteria analysis model is that it can overcome the limitations of the existing approaches in an intuitionistic fuzzy environment. The fuzzy multicriteria group decision making model can provide organizations with the ability to effectively evaluate the performance of their IoT-based supply chains for improving their competitiveness. A limitation of this research was the dependency of the decision outcome on the inputs provided by the decision makers. Future studies on this research area can include the development of a decision support system for assisting the decision makers in tackling the performance evaluation problem in a more efficient manner.

Author Contributions: S.W. was responsible for the writing the paper, developing the algorithm, and dealing with all calculations. S.G. was responsible for the literature review and providing the example.

Funding: This research received no external funding. 
Conflicts of Interest: The authors declare no conflict of interest.

\section{References}

1. Wang, X.; Liu, N. The application of Internet of Things in agricultural means of production supply chain management. J. Chem. Pharm. Res. 2014, 6, 2304-2310.

2. Govindan, K.; Soleimani, H.; Kannan, D. Reverse logistics and closed-loop supply chain: A comprehensive review to explore the future. Eur. J. Oper. Res. 2015, 240, 603-626. [CrossRef]

3. García, C.G.; Núñez-Valdez, E.R.; García-Díaz, V.; Pelayo G-Bustelo, C.; Cueva-Lovelle, J.M. A review of artificial intelligence in the Internet of Things. Int. J. Interact. Multimed. Artif. Intell. 2018, in press. [CrossRef]

4. Nallakaruppan, M.K.; Kumaran, U.S. Quick fix for obstacles emerging in management recruitment measure using IOT-based candidate selection. Serv. Oriented Comput. Appl. 2018, 1, 1-10. [CrossRef]

5. Huang, Y.P.; Basanta, H.; Singh, A. Assessing health symptoms on intelligent IoT-based healthcare system. Adv. Sci. Technol. Lett. 2017, 144, 21-30.

6. Dachyar, M.; Risky, S.A. Improving operational system performance of Internet of Things (IoT) in Indonesia telecomunication company. IOP Conf. Ser. Mater. Sci. Eng. 2014, 58, 1-5. [CrossRef]

7. Hwang, C.L.; Yoon, K.P. Multiple Attributes Decision Making Methods and Applications; Springer: Berlin, Germany, 1981.

8. Saaty, T.L. The Analytic Hierarchy Process; McGraw-Hill: New York, NY, USA, 1980.

9. Valacich, J.; Schneider, C. Information Systems Today: Managing in the Digital World; Pearson Education Limited: Hoboken, NJ, USA, 2014.

10. Molano, J.I.R.; Lovelle, J.M.C.; Montenegro, C.E.; Granados, J.J.R.; Crespo, R.G. Metamodel for integration of internet of things, social networks, the cloud and industry 4.0. J. Ambient Intell. Humaniz. Comput. 2018, 9, 709-723. [CrossRef]

11. Morente-Molinera, J.A.; Kou, G.; González-Crespo, R.; Corchado, J.M. Solving multi-criteria group decision making problems under environments with a high number of alternatives using fuzzy ontologies and multi-granular linguistic modelling methods. Knowl.-Based Syst. 2017, 137, 54-64. [CrossRef]

12. Lee, I.; Lee, K. The Internet of Things (IoT): Applications, investments, and challenges for enterprises. Bus. Horiz. 2015, 58, 431-440. [CrossRef]

13. Abdel-Basset, M.; Manogaran, G.; Mohamed, M. Internet of Things (IoT) and its impact on supply chain: A framework for building smart, secure and efficient systems. Future Gener. Comput. Syst. 2018, 86, 614-628. [CrossRef]

14. Wibowo, S. A Fuzzy Approach for Evaluating the Performance of Supply Chain based on Internet of Things. In Proceedings of the IEEE International Conference on Cyber Technology in Automation, Control, and Intelligent Systems (IEEE-CYBER 2012), Bangkok, Thailand, 27-31 May 2012.

15. Decker, C.; Berchtold, M.; Chaves, L.W.; Beigl, M.; Roehr, D.; Riedel, T.; Herzig, D. Cost-benefit model for smart items in the supply chain. Internet Things 2008, 1, 155-172.

16. Huang, J.; Xu, L.; Xing, C.; Duan, Q. A novel bioinspired multiobjective optimization algorithm for designing wireless sensor networks in the Internet of Things. J. Sens. 2015, 1, 1-16. [CrossRef]

17. Nunes, L.H.; Estrella, J.C.; Perera, C.; Reiff-Marganiec, S.; Delbem, A.C. Multi-criteria IoT resource discovery: A comparative analysis. Softw. Pract. Exper. 2017, 47, 1325-1341. [CrossRef]

18. Fan, S.; Shi, W.; Wang, N.; Liu, Y. MODM-based evaluation model of service quality in the Internet of Things. Pocedia Environ. Sci. 2011, 11, 63-69.

19. Du, J.; Zhao, L.; Feng, J.; Chu, X. Computation offloading and resource allocation in mixed fog/cloud computing systems with min-max fairness guarantee. IEEE Trans. Commun. 2018, 66, 1594-1608. [CrossRef]

20. Habib, M.S.; Sarkar, B. An integrated location-allocation model for temporary disaster debris management under an uncertain environment. Sustainability 2017, 9, 716. [CrossRef]

21. Welbourne, E.; Battle, L.; Cole, G.; Gould, K.; Rector, K.; Raymer, S.; Balazinska, M.; Borriello, G. Building the Internet of Things using RFID: The RFID ecosystem experience. IEEE Internet Comput. 2009, 13, 48-55. [CrossRef]

22. Atzori, L.; Iera, A.; Morabito, G. The Internet of Things: A survey. Comput. Netw. 2010, 54, $2787-2805$. [CrossRef]

23. Chui, M.; Loffler, M.; Roberts, R. The internet of things. McKinsey Q. 2010, 2, 70-79. 
24. Zanella, A.; Bui, N.; Castellani, A.; Vangelista, L.; Zorzi, M. Internet of Things for smart cities. IEEE J. Internet Things 2014, 1, 22-32. [CrossRef]

25. Brody, P.; Pureswaran, V. The next digital gold rush: How the Internet of Things will create liquid, transparent markets. Strategy Leadersh. 2015, 43, 36-41. [CrossRef]

26. Martinho, R.; Domingos, D. Quality of information and access cost of IoT resources in BPMN processes. Procedia Technol. 2014, 16, 737-744. [CrossRef]

27. Kouicem, D.E.; Bouabdallah, A.; Lakhlef, H. Internet of things security: A top-down survey. Comput. Netw. 2018, 141, 199-221. [CrossRef]

28. Zhao, Y.L.; Benedetto, C.A. Designing service quality to survive: Empirical evidence from Chinese new ventures. J. Bus. Res. 2013, 66, 1098-1107. [CrossRef]

29. Thaichon, P.; Lobo, A.; Prentice, C.; Quach, T.N. The development of service quality dimensions for Internet service providers: Retaining customers of different usage patterns. J. Retail. Consum. Serv. 2014, 21, 1047-1058. [CrossRef]

30. Macaulay, T. Interoperability, flexibility, and industrial design requirements in the IoT. RIoT Control 2017, 1, 197-219.

31. Kryvinska, N.; Strauss, C. Conceptual model of business services availability vs. interoperability on collaborative IoT-enabled eBusiness platforms. Stud. Comput. Intell. 2013, 1, 167-187.

32. Dehury, C.K.; Sahoo, P.K. Design and implementation of a novel service management framework for IoT devices in cloud. J. Syst. Softw. 2016, 119, 149-161. [CrossRef]

33. Chin, W.S.; Kim, H.S.; Heo, Y.J. A context-based future network infrastructure for IoT services. Procedia Comput. Sci. 2015, 56, 266-270. [CrossRef]

34. Olivier, F.; Carlos, G.; Florent, N. New security architecture for IoT network. Procedia Comput. Sci. 2015, 52, 1028-1033. [CrossRef]

35. Gubbi, J.; Buyya, R.; Marusic, S.; Palaniswami, M. Internet of Things (IoT): A vision, architectural elements, and future directions. Future Gener. Comput. Syst. 2013, 29, 1645-1660. [CrossRef]

36. Sarkar, S. Internet of Things-Robustness and reliability. Internet Things 2016, 1, 201-218.

37. Hersent, O.; Elloumi, O.; Boswarthick, D. The Internet of Things: Key Applications and Protocols; John Wiley and Sons: Milton, Queensland, Australia, 2011.

38. Farooq, M.U.; Waseem, M.; Khairi, A.; Mazhar, S. A critical analysis on the security concerns of Internet of Things (IoT). Int. J. Comput. Appl. 2015, 111, 1-8.

39. Weber, R.H. Internet of Things-New security and privacy challenges. Comput. Law Secur. Rev. 2010, 26, 23-30. [CrossRef]

40. Gaona-García, P.; Montenegro-Marin, C.; Prieto, J.D.; Nieto, Y.V. Analysis of security mechanisms based on clusters IoT environments. Int. J. Interact. Multimed. Artif. Intell. 2017, 4, 55-60. [CrossRef]

41. Atanassov, K. Intuitionistic fuzzy sets. Fuzzy Sets Syst. 1996, 20, 87-96. [CrossRef]

42. Wibowo, S.; Deng, H. Consensus-based decision support for multicriteria group decision making. Comput. Ind. Eng. 2013, 66, 625-633. [CrossRef]

43. Yeh, C.H.; Deng, H.; Wibowo, S.; Xu, Y. Multicriteria group decision for information systems project selection under uncertainty. Int. J. Fuzzy Syst. 2010, 12, 170-179.

44. Chen, S.M.; Cheng, S.H.; Lan, T.C. A novel similarity measure between intuitionistic fuzzy sets based on the centroid points of transformed fuzzy numbers with applications to pattern recognition. Inf. Sci. 2016, 343, 15-40. [CrossRef]

45. Lin, L.; Yuan, X.H.; Xia, Z.Q. Multicriteria fuzzy decision-making methods based on intuitionistic fuzzy sets. J. Comput. Syst. Sci. 2007, 73, 84-88. [CrossRef]

46. Xia, M.; Xu, Z. Hesitant fuzzy information aggregation in decision making. Int. J. Approx. Reason. 2011, 52, 395-407. [CrossRef]

47. Hashemi, S.S.; Hajiagha, S.H.; Zavadskas, E.K.; Mahdiraji, H.A. Multicriteria group decision making with ELECTRE III method based on interval-valued intuitionistic fuzzy information. Appl. Math. Modell. 2016, 40, 1554-1564. [CrossRef]

(C) 2018 by the authors. Licensee MDPI, Basel, Switzerland. This article is an open access article distributed under the terms and conditions of the Creative Commons Attribution (CC BY) license (http://creativecommons.org/licenses/by/4.0/). 